\title{
Complexed Ascorbic Acid for Topical Applications
}

\begin{abstract}
Ascorbic acid (vitamin C, AA) has found legendary applications in topical and skin antiaging products. The stability of $A A$ in aqueous based formulations in the presence of light, heat, and air has posed significant consumer and marketing concerns. A number of approaches, from the entrapment or encapsulation of AA to its derivatization, have been reported. The relative efficacy, availability, and cost viability of these routes have yet to provide a universally acceptable solution. The most direct approach, the stabilization of AA itself in water-based formulations with the inclusion of alkali metal bicarbonate, is reported herein. The chemical mechanism of this stabilization remains unknown
\end{abstract}

\section{Introduction}

Ascorbic acid (vitamin C, AA) performs legendary biological functions, such as the stimulation of collagen synthesis, the strengthening of skin tissues against attack by external antagonists (UV radiation, pollution), reduction in loss of pigmentation, activity against free radicals and compensation for vitamin B deficiency. A wide spectrum of topical applications of AA is summarized in Table $1[1-21]$.

Cellular biology is catalyzing renewed interest in AA in the management of a variety of human health and wellness concerns. Epigenetic regulation by AA has recently been discovered. An epigenetic change regulates the activity of single genes by the addition of a chemical compound [22].

Vitamin C exists predominantly as an ascorbate anion under physiological $\mathrm{pH}$ conditions. Ascorbate was discovered as a cofactor for methylcytosine dioxygenases that are responsible for DNA demethylation. Ascorbate deficiency could potentially be involved in embryonic and postnatal development, and plays a role in various diseases such as neurodegeneration (Alzheimer's) and cancer through epigenetic downregulation [22].

Ascorbate also serves as a cofactor for Ten-eleven translocation (TET) dioxygenases that catalyze the oxidation of 5-methylcytosine (5-mC) into 5-hydroxymethylcytosine $(5-\mathrm{hmC})$, and further to 5 -formylcytosine (5-fC) and to 5-carboxylcytosine (5-caC), which are ultimately replaced by unmodified cytosine. The Jumonji C (JmjC)domain-containing histone demethylases also requires ascorbate as a cofactor for histone demethylation. By primarily participating in the demethylation of both DNA and histones, ascorbate appears to be a mediator of the interface between the genome and environment. This highlights potential epigenetic roles of ascorbate in various diseases [23-25].

AA is known to be responsible for maintaining the efficacy and the phagocytosis activity of leucocytes. AA also plays a role in osteogenesis by the activation of alkaline phosphatase and increase in the functional activity of osteoblasts [26].

\section{Journal of}

\section{Clinical \& Investigative} Dermatology

\section{David Peter ${ }^{1}$, Melinda Wochner ${ }^{1}$ and Shyam Gupta ${ }^{2 *}$}

${ }^{\prime}$ CoValence Laboratories, Inc., Chandler, Arizona, 85224, USA

${ }^{2}$ Bioderm Research, Scottsdale, Arizona, 85254, USA

\section{Address for Correspondence}

Shyam Gupta, Bioderm Research, Scottsdale, Arizona, 85254, USA, E-mail: shyam@biodermresearch.com

Submission: 26 May, 2016

Accepted: 06 June, 2016

Published: 10 June, 201

Copyright: (c) 2016 Peter D, et al. This is an open access article distributed under the Creative Commons Attribution License, which permits unrestricted use, distribution, and reproduction in any medium, provided the original work is properly cited.

Reviewed \& Approved by: Taihao Quan, Department of Dermatology University of Michigan, USA

Root resorption (RR) is defined as the loss of dental hard tissues inside of tooth and root. RR is a pathologic event that can result in the premature loss of the affected tooth. AA has properties of tissue repair, which might play an important role in tooth therapy [27].

AA is known to act as a prooxidant in the oxidative breakdown of fat in fatty meat products. Cytotoxic and genotoxic lipid oxidation products (malondialdehyde, 4-hydroxy-2-nonenal, volatile aldehydes), protein oxidation products (protein carbonyl compounds) and NOC-specific DNA adducts (O6-carboxy-methylguanine) are thus produced. Lipophilic reducing agents, $a$-tocopherol, quercetin and silibinin, exerted an antioxidant effect. This is of significance in the oral intake of vitamins during food intake of many fatty meat preparations $[28,29]$.

The stability of AA has posed concerns, especially in water-based compositions that seem to be unstable in the presence of air and light, and exposure to heat. In a recent study, oxygen was shown to catalyze one-electron oxidation of AA via two separate mechanisms to produce hydrogen peroxide, which, in itself, is a potent oxidizing agent causing further oxidation of AA [30]. At higher temperatures, AA completely disappeared after 5 months stored in a buffer medium. AA instability to higher temperatures in capsicum preparations was similarly noted. The antioxidant properties of ascorbic acid are negatively influenced by both the moisture content and storage temperature [31-33].

A number of approaches to stabilize AA ranging from encapsulation to derivatization have been reported. For example, nanocapsules made with poly (ethyl-2-cyanoacrylate provided protection of AA from oxidation and presented superior storage stability in aqueous medium than pure AA. Several other micro-and nano-capsules and liposomes of AA have been reported [34-38].

The preparation of lipophilic ascorbyl esters has received much attention as a possible solution to the instability of (hydrophilic) AA in water-based compositions. Alkyl esters of AA with different acyl chain lengths were found to be stable toward oxidation, possibly due 


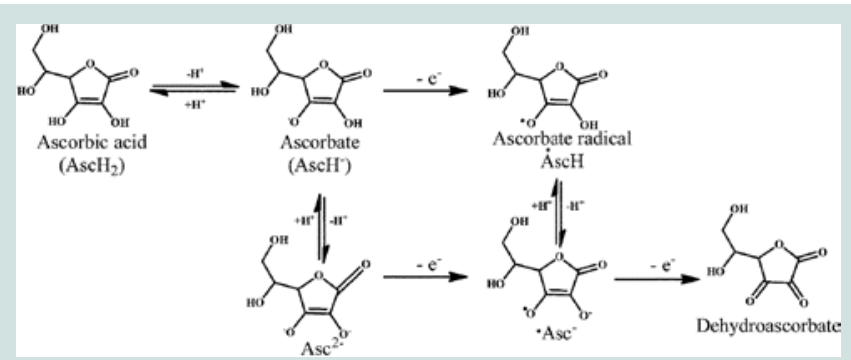

Figure 1: Antioxidant mechanism of ascorbic acid [42].

to a tautomeric isomerization. AA esters with the longer acyl chain (C-16, C-14 and C-12) have exhibited good surfactant activity [39].

The surfactant activity, extraneous to AA's antioxidant property, may not be a desirable attribute in certain topical compositions from efficacy and drug safety considerations. For example, 6-O-Ascorbic acid alkanoates are amphiphilic molecules having physical-chemical properties that depend on the alkyl chain length. Longer length of the hydrophobic chain can turn these into either micellar solutions or gel phases, which can enhance the penetration of other constituents present in the same composition into skin. In practical terms, certain ascorbyl esters have been noted to enhance skin penetration of vitamin $\mathrm{E}$ and other lipophilic agents (topical ibuprofen, for example) that may be copresent in a water-based formulation $[40,41]$.

Additionally, the comparative in vivo antioxidant efficacy of ascorbic acid and its ester or other derivatives is relatively unknown. The stability issue has received more focus than their relative efficacy, accessibility, or cost viability parameters in formulating AA derivatives.

On theoretical basis alone, the two free hydrogen atoms bonded to $\mathrm{C}=\mathrm{C}$ bond in $\mathrm{AA}$ can be utilized in the capture of free radicals to provide antioxidant benefits (Figure 1) [42].

This would indicate that, in comparison to itself, any esters or derivatives of AA that have one or both of these functional-OH groups blocked may have a compromised antioxidant activity. However, any such comparative data on a molar equivalence basis seem not to exist. It appears that the esters of AA may be hydrolyzing in vivo to release AA, which then provides the antioxidant action [43]. To illustrate this further, calculated molar equivalents of select AA derivatives are noted in Table 3. This could indicate the relative amounts of AA esters required to deliver equivalent antioxidant benefit, as per the above AA ester hydrolysis theory. Resolutive research is required.

The examples noted above bring to focus the complexity of AA stabilization via encapsulation and derivatization methods. Formulating AA itself in stabilized topical products offers a most direct, cost viable, easily accessible, and possibly most efficacious route.

Keep it Simple \& Safe (KISS): this philosophy of formulating consumer-preferred products has resulted in a very simple method for stabilized AA. It has now been discovered that the inclusion of alkali metal bicarbonates in aqueous-based formulations provides stabilized AA. The use of alkali metal carbonates and hydroxides via identical methodology results in unstable formulations [44]. It is worthy of note that sodium ascorbate, made from AA and sodium bicarbonate, is also unstable [44]. Sodium ascorbate, in a solid form, does not suffer from such instability. The reason for unexpected stability of AA/ bicarbonate/water system reported herein is not known.

Table 1: Topical applications of ascorbic acid.

1. Topical ascorbic acid on photoaged skin [2].

2. Ascorbic Acid for the safe use of a sunscreen agent [3].

3. Split-face study of topical $23.8 \%$ L-ascorbic acid serum in treating photo-aged skin [4]

4. The study of absorption efficiency and restoring effects of collagen and ascorbic acid on aged skin [5].

5. Induction of collagen synthesis by ascorbic acid $[6,7]$.

6. Ascorbic acid enhances the expression of collagen in human skin fibroblasts [8].

7. The effects of topical I(+) lactic Acid and ascorbic Acid on skin whitening [9].

8. Ascorbic acid for the healing of skin wounds [10].

9. The role of vitamin $C$ in pushing back the boundaries of skin aging [11]

10. Split-face vitamin C consumer preference study [12]

11. Improved scar appearance with combined use of silicone gel and vitamin $C$ [13].

12. Vitamin C possesses benefits including protection from UV A \& B, neocollagenesis, inhibition of melanogenesis and improvement of inflammatory skin disorders [14].

13. Use of topical nanosome vitamin $C$ iontophoresis in the treatment of melasma [15].

14. Sodium L-ascorbyl-2-phosphate for the treatment of acne vulgaris [16].

15. The cosmetic treatment of wrinkles [17].

16. Ascorbic acid causes reduction of oxidative stress, improvement of the epidermal-dermal microstructure and reduction of fine lines and wrinkles in aged skin [18]. 17. Sodium ascorbate elastogenesis [19].

18. Topical ascorbic acid treatment for skin disorders [20].

19. Anti-wrinkle Effect of Ascorbic Acid [21] 
Table 2: Stability of Ascorbic Acid (AA) preparations.

\begin{tabular}{|c|c|c|c|c|c|}
\hline Sample & $\begin{array}{c}\text { Freshly Made } \\
\text { pH }\end{array}$ & $\begin{array}{c}\text { Ambient } \\
1 \text { Month } \\
\mathrm{pH}\end{array}$ & $\begin{array}{c}40 \mathrm{C} \\
1 \text { Month } \\
\mathrm{pH}\end{array}$ & $\begin{array}{c}40 \mathrm{C} \\
1 \text { Month } \\
\text { Visual }\end{array}$ & $\begin{array}{c}40 \mathrm{C} \\
1 \text { Month } \\
\text { AA Analysis, } \\
\%\end{array}$ \\
\hline $\begin{array}{l}\text { Example I } \\
25 \%(A A)\end{array}$ & 1.87 & 1.93 & 1.68 & Darkening & 19.02 \\
\hline $\begin{array}{c}\text { Example II } \\
25 \% \text { AA + } \\
\mathrm{NaHCO}_{3}\end{array}$ & 6.20 & 6.24 & 6.34 & Clear & 26.73 \\
\hline $\begin{array}{c}\text { Example III } \\
25 \% \mathrm{AA}+ \\
\mathrm{Na}_{2} \mathrm{CO}_{3}\end{array}$ & 9.84 & 9.89 & 9.70 & Darkening & 24.81 \\
\hline $\begin{array}{c}\text { Example IV } \\
25 \% \mathrm{AA}+ \\
\mathrm{NaOH}\end{array}$ & 5.04 & 5.15 & 5.37 & Clear & 21.79 \\
\hline
\end{tabular}

Table 3: Calculated molar equivalents (me) of Ascorbic Acid (AA) and AA derivatives.

\begin{tabular}{|c|c|}
\hline AA/AA Derivative & Calculated ME \\
\hline Ascorbic Acid & 174 \\
\hline Na Ascorbyl PO4 & 276 \\
\hline Ascorbyl Palmitate & 414 \\
\hline Ascorbyl Glucoside & 338 \\
\hline Tetrahexadecyl Ascorbate & 1136 \\
\hline
\end{tabular}

\section{Materials and Methods}

\section{Preparation of samples for stability testing}

All weights are in weight $\%$. Temperatures are in ${ }^{\circ} \mathrm{C}$.

Example 1: Preparation of Ascorbic Acid (25\%) and Water with Additional Ingredients (Control Sample for stability).

Ingredients: (1) Water 68.49 (2) Ascorbic acid, 25.00 (3) Beta Fructan 0.05 (4) Glucosamine hydrochloride 0.05 (5) Red wine concentrate 0.01 (6) Preservative 1.1 (7) Potassium sorbate 0.05 (8) Hydrolite-5 5.00 (9) Amigum 0.25.

Processing: The preparative methodology has been reported elsewhere [44].

Example 2: Preparation of the Complex of Ascorbic Acid (25\%) and Sodium Bicarbonate with Additional Ingredients.

Ingredients: (1) Water 56.56 (2) Ascorbic acid, 25.00 (3) Sodium bicarbonate 11.93 (4) Beta Fructan 0.05 (5) Glucosamine hydrochloride 0.05 (6) Red wine concentrate 0.01 (7) Preservative 1.1 (8) Potassium sorbate 0.05 (9) Hydrolite-5 5.00 (10) Amigum 0.25.

Processing: The preparative methodology has been reported elsewhere [44].

Example 3: Preparation of the complex of Ascorbic Acid (25\%) and Sodium Carbonate (1:1 molar ratio) with Additional Ingredients.

Ingredients: (1) Water 53.45 (2) Ascorbic acid, 25.00 (3) Sodium carbonate 15.04 (4) Beta Fructan 0.05 (5) Glucosamine hydrochloride 0.05 (6) Red wine concentrate 0.01 (7) Preservative 1.1 (8) Potassium sorbate 0.05 (9) Hydrolite-5 5.00 (10) Amigum 0.25.

Processing: The preparative methodology has been reported elsewhere [44].

Example 4: Preparation of Ascorbic Acid (25\%) and Sodium Hydroxide with Additional Ingredients.

Ingredients: (1) Water 40.09 (2) Ascorbic acid, 25.00 (3) Sodium Hydroxide (20\% solution) 28.40 (4) Beta Fructan 0.05 (5) Glucosamine hydrochloride 0.05 (6) Red wine concentrate 0.01 (7) Preservative 1.1 (8) Potassium sorbate 0.05 (9) Hydrolite-5 5.00 (10) Amigum 0.25.

Processing: The preparative methodology has been reported elsewhere.

\section{Stability testing of samples from examples 1 to 4}

Procedure: The samples of examples 1 to 4 are stored at room temperature and also at $40{ }^{\circ} \mathrm{C}$ in a container having air space on the top for a period of time. USP Ascorbic Acid Injection Method (ACCU Labs test method C-015) was used to determine ascorbic acid content. Any changes in color or $\mathrm{pH}$ were also recorded. These data are summarized in Table 2.

\section{Results and Discussion}

The data in Table 2 clearly show the stability of AA formulations in aqueous media in the presence of alkali metal bicarbonate, even with the inclusion of other skin beneficial agents and processing aids. AA formulations in aqueous media with alkali metal carbonates or hydroxides were unstable under comparative conditions.

\section{Conclusion}

Formulation of AA in combination with alkali metal bicarbonate in water-based systems provides heat, light, and air stable compositions. This offers a simple solution to stability concerns relative to AA-based formulations. Ascorbic acid is thus now available for a plethora of topical applications reported in Table 1.

\section{References}

1. England S, Seifter S (1986) The biochemical functions of ascorbic acid. Ann Rev Nutri 6: 365-406.

2. Humbert PG, Haftek M, Creidi P, Lapière C, Nusgens B, et al. (2003) Topical ascorbic acid on photoaged skin. Clinical, topographical and ultrastructural evaluation: double-blind study vs. placebo. Exp Dermatol 12: 237-244.

3. Fathi-azarbayjani A, Tan PL, Chan YY, Chan SY (2013) Ascorbic acid for the safe use of a sunscreen agent: accumulation of nano zinc oxide and titanium dioxide on the skin. Sci Pharm 81: 1141-1150.

4. Xu TH, Chen JZ, Li YH, Wu Y, Luo YJ, et al. (2012) Split-face study of topical $23.8 \% \mathrm{~L}$-ascorbic acid serum in treating photo-aged skin. J Drugs Dermatol 11: $51-56$.

5. Zhang Y, Jia YH, Chen JW, Liu Y, Shen XJ, et al. (2012) Application progress of laser-induced breakdown spectroscopy for surface analysis in materials science field. Guang Pu Xue Yu Guang Pu Fen Xi 32: 1441-1446.

6. Kitt DQ (2016) Arterial Tortuosity Syndrome reveals function of dehydroascorbic acid in collagen and elastin synthesis: implications for skin care. Med Hypotheses 87: 8-9.

7. Pinnel SR, Murad S, Darr D (1987) Induction of collagen synthesis by ascorbic acid. A possible mechanism. Arch Dermatol 123: 1684-1686.

8. Kishimoto Y, Saito N, Kurita K, Shimokado K, Maruyama N, et al. (2013) Ascorbic acid enhances the expression of type 1 and type 4 collagen and SVCT2 in cultured human skin fibroblasts. Biochem Biophys Res Commun 430: $579-584$.

9. Smith WP (1999) The effects of topical I(+) lactic Acid and ascorbic Acid on 
skin whitening. Int J Cosmet Sci 21: 33-40.

10. Lima CC, Pereira AP, Silva JR, Oliveira LS, Resck MC, et al. (2009) Ascorbic acid for the healing of skin wounds in rats. Braz J Biol 69: 1195-1201.

11. Crisan D, Roman I, Crisan M, Scharffetter-Kochanek K, Badea R (2015) The role of vitamin $C$ in pushing back the boundaries of skin aging: an ultrasonographic approach. Clin Cosmet Investig Dermatol 8: 463-470.

12. Baumann L, Duque DK, Schirripa MJ (2014) Split-face vitamin C consumer preference study. J Drugs Dermatol 13: 1208-1213.

13. Yun IS, Yoo HS, Kim YO, Rah DK (2013) Improved scar appearance with combined use of silicone gel and vitamin $\mathrm{C}$ for Asian patients: a comparative case series. Aesthetic Plast Surg 37: 1176-1181.

14. Stamford NP (2012) Stability, transdermal penetration, and cutaneous effects of ascorbic acid and its derivatives. J Cosmet Dermatol 11: 310-317.

15. Sobhi RM, Sobhi AM (2012) A single-blinded comparative study between the use of glycolic acid $70 \%$ peel and the use of topical nanosome vitamin C iontophoresis in the treatment of melasma. J Cosmet Dermatol 11: 65-71.

16. Woolery-Lloyd H, Baumann L, Ikeno H (2010) Sodium L-ascorbyl-2phosphate $5 \%$ lotion for the treatment of acne vulgaris: a randomized, double-blind, controlled trial. J Cosmet Dermatol 9: 22-27.

17. Rona C, Vailati F, Berardesca E (2004) The cosmetic treatment of wrinkles. J Cosmet Dermatol 3: 26-34.

18. Raschke T, Koop U, Düsing HJ, Filbry A, Sauermann K, et al. (2004) Topical activity of ascorbic acid: from in vitro optimization to in vivo efficacy. Skin Pharmacol Physiol 17: 200-206.

19. (2013) Integrated controller solution for monitoring and controlling manufacturing equipment. US Pat Appl 2013184337 (A1)

20. Serrano G, Almudéver P, Serrano JM, Milara J, Torrens A, et al. (2015) Phosphatidylcholine liposomes as carriers to improve topical ascorbic acid treatment of skin disorders. Clin Cosmet Investig Dermatol 8: 591-599.

21. Lee C, Yang H, Kim S, Kim M, Kang H, et al. (2015) Evaluation of the antiwrinkle effect of an ascorbic acid-loaded dissolving microneedle patch via a double-blind, placebo-controlled clinical study. Int J Cosmet Sci [Epub ahead of print].

22. Camarena V, Wang $G$ (2016) The epigenetic role of vitamin $C$ in health and disease. Cell Mol Life Sci 1645-1658.

23. Young JI, Züchner S, Wang G (2015) Regulation of the epigenome by vitamin C. Annu Rev Nutr 35: 545-564.

24. Dickson KM, Gustafson CB, Young JI, Züchner S, Wang G (2013) Ascorbateinduced generation of 5-hydroxymethylcytosine is unaffected by varying levels of iron and 2-oxoglutarate. Biochem Biophys Res Commun 439: 522527.

25. Blaschke K, Ebata KT, Karimi MM, Zepeda-Martínez JA, Goyal P, et al. (2013) Vitamin $C$ induces Tet-dependent DNA demethylation and a blastocyst-like state in ES cells. Nature 500: 222-226.

26. Goldschmidt MC (1991) Reduced bactericidal activity in neutrophils from scorbutic animals and the effect of ascorbic acid on these target bacteria in vivo and in vitro. Am J Clin Nutr 54(6 Suppl): 1214S-1220S.

27. Mohammadi Z, C Cehreli Z, Shalavi S, Giardino L, Palazzi F, et al. (2016) Management of root resorption using chemical agents: a review. Iran Endod J 11: $1-7$.

28. Van Hecke T, Wouters A, Rombouts C, Izzati T, Berardo A, et al. (2016)
Reducing compounds equivocally influence oxidation during digestion of a high-fat beef product, which promotes cytotoxicity in colorectal carcinoma cell lines. J Agric Food Chem 64: 1600-1609.

29. Van Hecke T, Vossen E, Vanden Bussche J, Raes K, Vanhaecke L, et al. (2014) Fat content and nitrite-curing influence the formation of oxidation products and NOC-specific DNA adducts during in vitro digestion of meat. PLoS One 9: e101122.

30. Boatright WL (2016) Oxygen dependency of one-electron reactions generating ascorbate radicals and hydrogen peroxide from ascorbic acid. Food Chem 196: 1361-1367.

31. Park JE, Kim KE, Choi YJ, Park YD, Kwon HJ (2016) The stability of waterand fat-soluble vitamin in dentifrices according to $\mathrm{pH}$ level and storage type. Biomed Chromatogr 30: 191-199.

32. Rahman MS, Al-Rizeiqi MH, Guizani N, Al-Ruzaiqi MS, Al-Aamri AH, et al. (2015) Stability of vitamin $C$ in fresh and freeze-dried capsicum stored at different temperatures. J Food Sci Technol 52: 1691-1697.

33. Kim JY, Kim MJ, Yi B, Oh S, Lee J (2015) Antioxidant properties of ascorbic acid in bulk oils at different relative humidity. Food Chem 176: 302-307.

34. Zhang SN, Chen T, Guo YG, Zhang J, Song X, et al. (2015) The stability and controlled release of I-ascorbic acid encapsulated in poly (ethyl-2cyanoacrylate) nanocapsules prepared by interfacial polymerization of waterin-oil microemulsions. J Cosmet Sci 66: 247-259.

35. Mayer C (2005) Nanocapsules as drug delivery systems. Int J Artif Organs 28: 1163-1171.

36. Khalid N, Kobayashi I, Neves MA, Uemura K, Nakajima M, et al. (2015) Monodisperse aqueous microspheres encapsulating high concentration of I-ascorbic acid: insights of preparation and stability evaluation from straightthrough microchannel emulsification. Biosci Biotechnol Biochem 79: 18521859.

37. Akhlaghi SP, Berry RM, Tam KC (2015) Modified cellulose nanocrystal for vitamin C delivery. AAPS PharmSciTech 16: 306-314.

38. Serrano G, Almudéver P, Serrano JM, Milara J, Torrens A, et al. (2015) Phosphatidylcholine liposomes as carriers to improve topical ascorbic acid treatment of skin disorders. Clin Cosmet Investig Dermatol 8: 591-599.

39. Mottola M, Vico RV, Villanueva ME, Fanani ML (2015) Alkyl esters of L-ascorbic acid: stability, surface behaviour and interaction with phospholipid monolayers. J Colloid Interface Sci 457: 232-242.

40. Palma S, Jiménez-Kairuz A, Fratoni L, Lo Nostro P, Manzo R, et al. (2003) Coagels from alkanoyl-6-O-ascorbic acid derivatives as drug carriers: structure and rheology. Farmaco 58: 1271-1276.

41. Segall Al, Moyano MA (2008) Stability of vitamin C derivatives in topical formulations containing lipoic acid, vitamins A and E. Int J Cosmet Sci 30: 453-458.

42. Nimse SB, Pal D (2015) Free radicals, natural antioxidants, and their reaction mechanisms. RSC 5 27986-28006.

43. Saino V, Monti D, Burgalassi S, Tampucci S, Palma S, et al. (2010) Optimization of skin permeation and distribution of ibuprofen by using nanostructures (coagels) based on alkyl vitamin $\mathrm{C}$ derivatives. Eur $\mathrm{J}$ Pharm Biopharm 76: 443-449.

44. Fox HH, Passaic, Creighton MM, Nutley NJ (1950) Method of preparing sodium 1-ascorbate. US Patent. 